\title{
La dimensión comunicativa del arte. Apuntes para un estado de la cuestión
}

\author{
Vivian Romeu Aldaya* \\ Universidad Autónoma de la CiUdad de México
}

Este trabajo hace un intento por mostrar algunos de los trayectos convergentes entre el arte y la comunicación. El rastreo centra su atención en los nodos conceptuales que marcan un cambio sustancial en la manera de entender los vínculos entre ambos campos, y con ello pretende una caracterización de la red conceptual en la que desemboca el panorama de las relaciones entre el campo del arte y el campo de la comunicación, a partir de lo que hemos determinado como dimensión comunicativa del arte. El objetivo, por tanto, es ofrecer una aproximación al estado de la cuestión sobre este tema y contribuir así a la consolidación de los estudios sobre este tópico.

Palabras clave: arte, comunicación, estado de la cuestión, estética.

This work makes an attempt show some of the convergent passages between the art and the communication. The tracking focuses its attention on the conceptual nodes that mark a substantial change in the way to understand the bonds between both fields, and with it it's tries a characterization of the conceptual network at which the panorama of the relations between

\footnotetext{
* Doctora en Comunicación Social por la Universidad de La Habana, Cuba. Profesora-investigadora de la Academia de Comunicación y Cultura de la Universidad Autónoma de la Ciudad de México. Miembro de la Asociación Mexicana de Investigadores en Comunicación (AMIC), miembro de la Red Internacional de Investigadores sobre la Frontera, miembro de la Asociación Latinoamericana de Estudios sobre el Discurso (ALED) y miembro del Consejo Editorial de Global Media Journal en Español. Ha publicado en numerosas revistas indixadas tanto nacionales como internacionales. Áreas de investigación: Arte y comunicación, Estética de la recepción, Semiótica y Comunicación Intercultural. Correo electrónico: mynameisariel@hotmail.com
} 
the field of the art and the one of the communication. All this supported by what we have defined as communicative dimension of the arts. The objective, therefore, is to offer an approach to the state of the question on this subject and to contribute thus to the consolidation of the studies on this topic.

Key words: arts, communication, state of the questions, aesthetics.

\section{ARTE Y COMUNICACIÓN: HACIA UNA APROXIMACIÓN}

\section{DE SUS TRAYECTORIAS CONCEPTUALES}

Para entender las relaciones campales entre arte y comunicación debemos referirnos a lo comunicativo como una instancia simbólica que organiza y configura las relaciones sociales entre sujetos y grupos, y a lo artístico como los fenómenos y prácticas propios del campo del arte. En ese sentido, y haciendo resumen de lo anterior, el arte -en tanto producto y práctica sociocomunicativa- resulta ser la manifestación también de un orden sociosimbólico histórico concreto (Bourdieu, 1995) que se construye y despliega en lo social desde lo comunicativo, es decir, desde la interrelación, interacción e intercambio entre sujetos y grupos de significados sobre la vida, el mundo y ellos mismos.

En tanto práctica comunicativa, entonces, el arte es instancia y fenómeno, obra y lugar desde donde los sujetos intercambian también sus sentidos de vida en un proceso a todas luces comunicativo. Sin embargo, a pesar de la evidencia de lo anterior, el arte y la comunicación han sido ámbitos de estudio perfectamente diferenciados a lo largo del tiempo, aunque algunas reflexiones desde los campos de la filosofía, la estética y la sociología han hecho tambalear esta separación; de la misma manera, numerosos análisis semióticos de corte empírico y teórico han contribuido a abonar el terreno a favor del estrechamiento de los vínculos entre el arte y la comunicación. La descripción, explicación y caracterización del panorama conceptual en el que estos trabajos se insertan resulta necesario para entender que el punto de convergencia entre estos campos se sostiene bajo lo que hemos denominado dimensión comunicológica del arte que no es más que el eje conceptual que en los textos estéticos permite hablar de diálogo, en tanto atributo comunicativo. ${ }^{1}$

\footnotetext{
${ }^{1}$ Para mayor información sobre este tópico, recomendamos indagar en el concepto de 'razón comunicativa' propuesto por Gerard Vilar en Las razones del arte, La Balsa de la Medusa, Barcelona, 2005, y el concepto de 'diálogo' desarrollado por la autora en "Arte y comunicación.
}

I24・Vivian Romeu Aldaya 
En función de lo anterior, hemos dividido el cuerpo de este trabajo en cinco partes desde donde es posible abordar dicha dimensión. Las cuatro primeras corresponden a los nodos conceptuales que figuran netamente como antecedentes directos, y la última parte agrupa una descripción sobre los trabajos que desde el interior del enfoque teórico-conceptual sobre la dimensión comunicativa de arte se han venido desarrollando a partir de las últimas décadas del siglo xx. No obstante, la caracterización que a continuación se pretende peca de esquemática toda vez que, en la realidad, los nodos forman parte unos de otros y no constituyen por sí mismos entidades estrictamente delimitadas.

\section{I. Los antecedentes}

Los antecedentes para comprender las relaciones entre arte y comunicación hay que rastrearlos, a nuestro entender, en torno a cuatro nodos conceptuales: el nodo estético-histórico que aborda la relación entre el arte y la vida desde una perspectiva contingente e histórica; el nodo estético-cognitivo que se enfoca en la concepción del arte como vehículo del conocimiento universal, es decir, del conocimiento de lo inmutable, de lo verdadero, y se ancla en una dimensión mayormente trascendentalista y metafísica; el nodo estético-intuitivo que reflexiona en torno a los procesos de creación del arte como procesos intuitivos, posicionándose con ello a las puertas de la comunicación en tanto concibe la expresión clara de lo intuido como el fin del arte; y el nodo estético-semiótico, que aborda semióticamente los procesos de interpretación en el arte como parte insoslayable de cualquier proceso comunicativo. Son exponentes de la primera postura Aristóteles, Hauser, Dewey, Collingwood y Adorno; de la segunda: Kant, Hegel, Heidegger, Gadamer y algunos teóricos de la Estética Pragmática; de la tercera Bayer, Croce y Pareyson; y de la cuarta Eco, Calabrese y Lotman.

\section{I.I.I. Nodo estético-histórico}

Aristóteles (1985) pensaba que el arte debía representar aquello que sin haber sucedido pareciera a los ojos de los espectadores real, pues sólo así se realizaría la catarsis como vía para la purificación del alma humana. Partiendo de la premisa de que lo que es posible es creíble, este filósofo definía a lo poético en función de lo catártico, en tanto permitía la identificación y la generación del impacto. Así, Aristóteles centraba su visión del arte en el efecto que éste producía en los individuos y enfatizando el uso comunicativo que a los efectos de la credibilidad

Apuntes para una reflexión sobre la comunicación artística”. En XIV Anuario CONEICC, 2007, pp. 203-220.

La dimensión comunicativa del arte. $\bullet_{\mathrm{I}} 25$ Apuntes para un estado de la cuestión 
se le daba a lo históricamente sucedido. ${ }^{2}$ Hauser (1994), en cambio, asigna a lo histórico un papel diferente; este sociólogo parte de que hay un vínculo entre los procesos artísticos y los procesos históricos-sociales, aunque reconoce que dichos vínculos se dan en el entrecruzamiento de múltiples factores históricos, sociales y económicos, por una parte, y las individualidades de los artistas, por la otra. ${ }^{3}$ Ello, además de apuntar a la libre relación entre el arte y el artista, y entre éstos y el público, resalta el hecho de que la obra es también fruto de un momento histórico concreto. Fue Dewey (citado en Vilar, 2005), no obstante, quien desde las primeras décadas del siglo XX, consolidó teóricamente la relación entre el arte y la historia, con su concepto de experiencia como relación e interconexión entre sujeto y sociedad.

En resumen, todo lo anterior implica que la creación artística es una actividad contingente gestada por el artista en connivencia con lo social, lo que coincide con la línea de pensamiento de Collingwood (1960) quien al tiempo que hace postular la naturaleza individual del acto creativo -definiendo al arte como la expresión de una emoción, una preocupación o un juicio de su autor- plantea que el autor se apropia de los lenguajes que tiene a su alcance (léase, lenguajes pre-existentes) para construir de manera original una obra; la creación de una obra, en palabras de este autor, es la creación también de un nuevo lenguaje. Por ello podemos afirmar que en Collingwood aparece claramente la idea de que el lenguaje estético es una "invención" del artista, aunque se trata de la invención de un lenguaje nuevo a partir de otros lenguajes, de ahí su propiedad dialógica.

Por último, cerramos este apartado refiriéndonos a las posturas de Adorno (1983), para quien el arte es contenido de la verdad, pero su verdad no es reflejo del objeto sino del pensar del artista, es decir, de la verdad de la Historia contenida en las experiencias del artista en tanto ser histórico que es; eso es el arte para Adorno: lo permanentemente verdadero. En ese sentido, la tesis adorniana propone al sentido de la legibilidad del arte como condición para el diálogo.

\footnotetext{
${ }^{2}$ Esta línea de pensamiento vincula a Aristóteles con los humanistas medievales, los Ilustrados e incluso con el pensamiento bretchiano para quienes la concepción de verosimilitud (racionalidad-intelectualidad) se define como criterio del arte.

${ }^{3}$ Dicha concepción desdogmatiza la relación entre cultura y sociedad, y se distancia de la sociología tradicional al reconocer que si bien el artista no puede sustraerse del contexto social en que vive y produce, su voluntad y creatividad individuales no pueden ser reducidas a meras causales históricas. De esta manera, Hauser admite que el valor artístico no tiene ningún equivalente sociológico, es decir, para este autor si bien el arte está condicionado por lo social, no puede ser explicado por lo social.
}

I 26 - Vivian Romeu Aldaya 


\section{I.1.2. Nodo estético-cognitivo}

Kant (1984) consideraba al arte como lo bello, y a lo bello como lo verdadero, pero para el filósofo idealista, lo bello refiere al objeto estético per se, y la belleza a la percepción del sujeto en torno a lo bello. He aquí justamente donde se funda, a nuestro juicio, el ideal comunicativo del arte para Kant: lo bello sólo puede ser perceptible por medio del juicio estético, es decir, del lenguaje, donde el papel del sujeto es insoslayable. Sólo que para Kant, el juicio estético no es lenguaje convencional, sino que se trata de lenguaje universal, o sea, lenguaje 'revelado' ${ }^{4}$ en la medida en que la imaginación, ligada al tiempo y al espacio concreto en el que se da en tanto percepción del objeto bello, constituye un apriori del sujeto.

Hegel (1982, citado en Sánchez Vázquez) en su idealismo radical, concibe al arte como conocimiento absoluto en tanto garantiza la aproximación al Espíritu Absoluto. Para el autor, el arte por su inmediatez natural a la Idea, constituye la apariencia sensible del Espíritu, es decir, lo que conecta al mundo sensible con el mundo superior. Dicha conexión hace pensar a Hegel que el arte es signo de lo superior y funge como vehículo de conocimiento entre un estadio y otro, idea que encuentra eco en el pensamiento de Gadamer (1991), para quien el arte no sólo es un revelador de "universales", es decir, de la esencia de las cosas, sino también un configurador de "nuevos universales nunca antes ejemplificados". Como se puede notar, para ambos autores la experiencia del arte es una forma especial de conocimiento; Hegel la concibe como aproximación al Espíritu Absoluto, y Gadamer, como la vía para enunciar la Verdad.

Según Gadamer, al captar el mundo libre de toda contingencia, es decir, de todo lo efímero y fortuito, el arte se llena de Verdad, orientándose con ello hacia lo universal de manera que lo que representa no vale por lo representado en sí mismo, sino por el proceso creativo individual (verdadero por más señas) a partir del cual ha llegado a representarse. Así, el conocimiento de las verdades eternas, que es el conocimiento universal y necesario, se revela a través de la actividad artística porque ésta es "intuición de lo verdadero" o como diría Platón reconocimiento del "deber ser de las cosas". En este reconocimiento hay siempre conocimiento del sí mismo implícito no en el conocimiento ordinario (la doxa) sino en el conocimiento de las verdades universales. Como afirma el propio Gadamer: "Lo que realmente se experimenta en una obra de arte, aquello

${ }^{4}$ Como puede notarse, Heiddeger resulta deudor del pensamiento kantiano, al afirmar que el arte "revela" lo no dicho.

La dimensión comunicativa del arte. $\bullet_{\mathrm{I} 27}$ Apuntes para un estado de la cuestión 
hacia lo que uno se polariza en ella, es más bien qué medida es verdadera, esto es, hasta qué punto uno conoce y reconoce en ella algo, y en este algo a sí mismo" (Gadamer, 1991, p. 158).

Desde la filosofía existencialista, pero en una dirección un tanto diferente a lo antes abordado, se halla Heidegger, para quien el camino a la Verdad, es decir, al Ser, es la actividad poética. Para este autor, el arte es lenguaje, y el lenguaje una aproximación a los orígenes del Ser por medio de la revelación. Heidegger (1983) rechaza la vía analítica para alcanzar este camino a la Verdad, y en consecuencia inhibe el aprendizaje de lo nuevo para fundar lo nuevo en el re-conocimiento del origen que es justamente lo que a su juicio, hace el arte. Su concepción del arte como obra puesta "por obra de la Verdad", resulta entonces sumamente sugerente para la comunicación en tanto enfatiza la circularidad del acto creativo, al tiempo que resalta el carácter aproximativo de este conocimiento. En ese sentido, resulta evidente el carácter mediador del arte en tanto lenguaje, es decir, en tanto vehículo y soporte de la comunicación.

Por último, desde la Estética Pragmática, y al abrigo de su fundador Baumgarten a fines del siglo XviII, comienza a desarrollarse una línea de pensamiento que coloca en el centro de la teoría estética a la experiencia cognitiva del sujeto. En esta recolocación varios autores juegan un papel importante, por ejemplo Wittgenstein (citado en Vilar, 2005) afirma que el arte, como parte de una práctica integrada social y lingüísticamente, es una forma de vida al igual que los juegos del lenguaje, por lo que es dicha y recibida según las reglas expresas (históricas en tanto sociales y lingüísticas) de dichos juegos. Esta aseveración también soporta otra definición importante, la de Mandelbaum (citado en Vilar, 2005), quien por su parte propone hablar de atributo relacional en el arte en tanto propiedad de los objetos artísticos, relación que involucra un objeto que ha sido creado por alguien para alguien. Como se puede observar hay en esta definición claros visos de comunicabilidad, y de ella son deudores dos estetas cuyas orientaciones son opuestas: Nelson Goodman, por una parte y Arthur Danto por la otra. Para Danto (2002), desde su perspectiva trascendental, el arte es un emboding meaning, es decir, un significado encarnado en la obra que el receptor tiene que comprender. Para Goodman (1976; 1990), mucho más pragmático, ${ }^{5}$ la experiencia del arte es una experiencia cognitiva que se distingue por el dominio de ciertas características simbólicas y se juzga por las normas de la eficacia cognoscitiva del sujeto a la hora de relacionarse

${ }^{5}$ Goodman no se pregunta por el arte, sino por cuándo hay arte.

I 28 - Vivian Romeu Aldaya 
interpretativamente con la obra. Todo lo anterior permite apuntar que la Estética Pragmática, reflexiona en torno a la posibilidad de que el receptor de arte no sólo 'contemple' la obra, sino que 'dialogue' con ella, y que mediante ese diálogo 'produzca' conocimiento. ${ }^{6}$

\section{I.I.3. Nodo estético-intuitivo}

Este nodo revela los vínculos entre el arte y los procesos de interpretación, que son ya procesos que tienen que ver con lo comunicativo propiamente dicho. Los antecedentes de estas reflexiones se hallan en los trabajos de la estética francesa e italiana del siglo XX, específicamente en las figuras de Raymond Bayer, Benedetto Croce, y Luigi Pareyson, fundamentalmente.

Bayer (citado en Eco, 1992), por ejemplo, consideraba a lo Bello como una experiencia abierta, es decir, como una serie de aproximaciones a la regla o canon estético, entendiendo así a la creación como un proceso interpretativo en el que confluyen infinidad de factores, incluidos los gustos y predilecciones personales. Sin embargo, para el esteta francés, el lenguaje tendrá una incidencia relevante en la interpretación en tanto le reconoce su intento de introducirse en el objeto estético ${ }^{7}$ que, no está demás aclarar, contiene, según Bayer, toda la predicación que se hace sobre él. Esto resulta contradictorio en el pensamiento del autor porque concibe simultáneamente al objeto estético como experiencia abierta y como algo completamente realizado, pero el sentido apertural que otorga a la experiencia estética en términos de indagación, replanteamiento y relación entre el objeto y el sujeto (postulados que también aparecen en Aristóteles -aunque de manera protointerpretativa-, en Gadamer y en Heidegger), revela la incidencia de la comunicación por vía del lenguaje, en ella.

\footnotetext{
${ }^{6}$ Para mayor información consultar: Romeu, V. (2007). "De la estética trascendental a la pragmática estética. Esbozos de una teoría comunicativa sobre el arte". En Revista de Filosofía Contemporánea Observaciones Filosóficas No. 5, Sección Estética y Teoría del Arte, 2do. semestre, julio. Artículo disponible en línea en: http://www.observacionesfilosoficas.net/delaestetica.html ${ }^{7}$ Bayer convierte al lenguaje en el único modo científico posible de interpretar el objeto, es decir, la cosa, y al preguntarse sobre quién o qué garantiza la exactitud de los garantizadores (los críticos que utilizan el lenguaje para intentar comprender el objeto estético), Bayer sostiene que es el objeto mismo el que es capaz de contener toda la predicación que se hace sobre él, a través de la comparación entre las estructuras de la obra y la predicación misma para reconocer o no en esta última las condiciones de validez del fenómeno vocabulario. Sin embargo, como observa Eco, este proceso de verificación exige "una concepción más dinámica, interactiva y procesual del objeto". (Eco, 1990, pp. 98-99).
} 
En otra dirección, la tesis de Croce (citado en Eco, 1992) sobre el arte como lenguaje refiere de forma clara, aunque errónea, que los sentimientos son comunicables y que los signos que aparecen estructurando a la obra "dicen algo”. Para este autor, el arte del artista es intuición del Espíritu, pero como el Espíritu del arte no es naturaleza ni historia, sólo puede expresarse mediante los sentimientos y las pasiones del propio artista que es el único capaz de intuir al Espíritu y expresarlo. Por ello, para Croce el arte es la expresión del Espíritu captado por la intuición individual, y el acto creador es actividad espiritual en la que el Espíritu está implicado mas no agotado o revelado del todo. ${ }^{8}$

Como se puede observar la concepción del arte de Croce no entiende al arte como representación de la realidad en tanto imitación de la naturaleza o verosimilitud histórica, sino más bien como representación de lo no representado, es decir, del Espíritu, mismo que al estar contenido en cada artista se manifiesta a través del arte por medio de la expresión. Una intuición no es tal si no se expresa (Croce, citado en Ruspoli 2000), por ello para el filósofo la creación artística y la expresión de los sentimientos del artista no pueden ser menos que el fin constitutivo de la actividad del arte.

Pareyson, por su parte, hace una crítica sagaz a Croce al plantear que la personalidad del artista no puede quedar absorbida en el universo de la obra, pues el carácter libremente activo del hombre (ya sea ejecutor o consumidor) incide en la obra en la medida en que la analiza, la discute y la comprende, manifestando en ello su propia personalidad. En su teoría de la Estética de la Formatividad, Pareyson (citado en Eco, 1990) señala que el acto creativo no es más que un 'modo de formar' del artista, instituyendo con ello la noción de creación como actividad formante esencialmente interpretativa. Así, este autor concibe a la actividad formativa como el acto de comunicación de una persona a otra, donde lo 'formado' pasa a ser no sólo memoria real del proceso formativo, sino forma formada a la manera personal e irrepetible del artista'. Como

\footnotetext{
${ }^{8}$ Según el autor, las diferentes creaciones artísticas son cada vez más ricas porque implican todos los estadios del Espíritu a la manera de un devenir histórico, por ello la interpretación del arte siempre crea nuevas obras distintas a la original. Aunque este concepto fue solamente aplicado por Croce a la poesía o al drama, discriminando a la música, el concepto en sí mismo resulta válido a la hora de hablar de la concepción de la comunicabilidad del arte en este autor.

${ }^{9}$ Pareyson cree que las formas son entidades indefinidas dotadas de legalidad autónoma, y en ese sentido se impone la fundamentación metafísica de un Configurador de Formas Supremo Este configurador de formas impide al artista interpretar las formas para adjudicarle un modo de formar propio; en cambio, lo que hace este Configurador Supremo es revelarle al artista
}

I 30 - Vivian Romeu Aldaya 
se puede notar, la teoría de Pareyson se opone a la de Croce; mientras que para el primero, el artista sólo se muestra como modo (he ahí lo que constituye el valor estético de una obra: su valor de organicidad), para el segundo, el artista se narra a sí mismo mediante la obra.

Pareyson define a la obra como un organismo estructurado, donde el artista se expresa en la medida en que le da forma a la forma, produciéndola de un modo suyo ${ }^{10}$. En ese sentido, la actividad artística se constituye como un intento o un esbozo de múltiples propuestas para intervenir la materia, pero la solución de tal o cual intervención corresponde al artista, es decir, al igual que en Croce, a la intuición de la forma a través de su genio y personalidad. ${ }^{11}$

A partir de lo anterior, se puede afirmar que en tanto en Bayer, como en Croce y Pareyson se hace presente la idea de la comunicabilidad intrínseca del arte, lo cual resulta relevante para los fines de este trabajo.

\section{I.I.4. Nodo estético-semiótico}

Otra cara del mismo asunto nos la revela Omar Calabrese en su libro ¿Cómo se lee una obra de arte? (Calabrese, 2001), en el que demuestra que los elementos presentes en algunas obras de arte que analiza puedan ser considerados lenguaje. Ello, si bien no puede vincularse quizá con un estatuto comunicativo fundante por parte del arte, sí nos parece pertinente resaltar la relación que este semiólogo concibe entre los elementos-signos constitutivos de una obra y la interpretación que los receptores puedan obtener y/o desencadenar a partir de la lectura de la misma. En ese sentido, según el autor, la obra despliega un estatuto comunicativo, al menos en acción, que se da precisamente en la relación interpretativa que se genera entre ella y el receptor.

Sin embargo, es en El lenguaje del arte (Calabrese, 1997) donde el autor desarrolla cuatro premisas básicas para articular las relaciones entre el arte y el lenguaje y sistematizar conceptualmente el estatuto comunicativo del $\operatorname{arte}^{12}$.

dichas formas, en el estilo.

10 "El artista, formando, inventa efectivamente leyes y ritmos nuevos, pero esta originalidad no nace de la nada, sino como libre resolución de un conjunto de sugestiones que la tradición cultural y el mundo fisico han propuesto al artista bajo la forma inicial de resistencia y pasividad codificada" (Pareyson, citado en Eco 1990, p. 19).

${ }^{11} \mathrm{La}$ intuición es también el mecanismo por excelencia que Croce maneja como formas de acceder a los sentimientos y a la verdad del artista. Consultar texto de Enrique Ruspoli (ver Bibliografía).

${ }^{12}$ En primer lugar señala al arte como una condición que poseen algunas obras que son produci-

La dimensión comunicativa del arte. $\bullet_{\mathrm{I} 3 \mathrm{I}}$ Apuntes para un estado de la cuestión 
Al afirmar que el arte es lenguaje, el autor señala que el arte depende de las propiedades comunicativas y de significación presentes en los objetos artísticos y que dichas propiedades deben tener el propósito de crear un sentido que manifieste sus valores estéticos, y que al mismo tiempo sean portadores de valores del gusto; en resumen el autor afirma que una teoría del arte con base comunicacional debe de ser capaz de dar cuenta de "cómo la obra dice aquello que dice", lo que nos resulta altamente significativo como un intento de definir las bases metodológicas para conceptualizar el sentido comunicativo del arte.

Umberto Eco, al igual que Calabresse, ha trabajado desde la semiótica las relaciones entre arte y lenguaje, y en particular los procesos de interpretación. En la introducción de Los límites de la Interpretación, obra que según el propio autor corrige algunos de los planteamientos de Obra Abierta, el autor marca de entrada su postura sobre el texto: "un texto flota (digámoslo asi) en el vacio de un espacio potencialmente infinito de interpretaciones posibles. Por consiguiente, ningún texto puede ser interpretado según la utopia de un sentido autorizado definido, original y final. El lenguaje dice siempre algo más que su inaccesible sentido literal, que se pierde ya en cuanto se inicia la omisión textual" (Eco, 1992, p. 10); sin embargo, adelantándose a la supuesta democratización de la recepción textual arguye inmediatamente después que no puede decirse tampoco, y a pesar de lo anterior, que el mensaje pueda significar cualquier cosa: "existe en el texto al menos algo que el mensaje no puede efectivamente decir" (Eco, 1992, p. 14), para concluir de una manera categórica, que "los límites de la interpretación coinciden con los derechos del texto" (Eco, 1992, p. 19).

Esto conduce al semiólogo a la conceptualización de tres aspectos de la intención: la intención del autor, la intención del texto y la intención de receptor, que constituyen en sí mismas categorías comunicativas en tanto categorías de interpretación. A partir de ello, Eco plantea que la intención del autor se manifiesta cuando crea un texto siguiendo una idea predeterminada sobre los significados y los efectos que deben generar éstos en el momento de la lectura; sin embargo, dicha intención puede que no estén manifiestas de forma fiel en el texto cons-

das con fines estéticos y de la producción general de objetos producidos con un efecto estético; en segundo lugar, considera al arte como un lenguaje que tiene que estar regido por reglas que lo hagan ser un sistema coherente, organizado y funcional; la tercera se enfoca en la distinción entre lo artístico y lo estético, considerando a esta última cualidad de la primera, misma que tiene que ser explicada como organización dependiente de la forma de comunicar de los objetos artísticos mismos; y por último, que sea dependiente de la forma en que son construidos los objetos artísticos también el efecto estético que éstos produzcan.

I 32 - Vivian Romeu Aldaya 
truido ya que el autor en el momento de la enunciación de su mensaje precisa de "habilidad" y "competencia" para llevar por buen camino sus intenciones iniciales, siendo que éstas pueden modificarse en el transcurso de la enunciación. Es decir, la intención del texto, producida a través de su estrategia textual puede o no estar vinculada con la intención previa del emisor al crearlo.

La propuesta de Eco exige así centrar la intención del texto (intentio operis), como categoría con la que opera en primera y última instancia el proceso de interpretación, y ello supone que el acceso a ella se construya por medio de la aproximación conjetural del receptor. La intentio operis así entendida, no es más que la estrategia textual por la que el texto, en relación estrecha con el lector, "produce" un determinado sentido, mismo que al decir del propio Eco "sólo puede ser aceptado si es confirmado -o al menos si no es puesto en tela de juiciopor otro punto del texto". Así, la intención textual queda sujeta por una parte, a la gama de opciones conjeturales que el lector puede proponerse para abordar el texto (intención de lector), y por la otra, a la malla de sentidos que el texto mismo "aprueba" para sí o permite. Es el acto de partir precisamente del hecho consumado de la interpretación de textos literarios, lo que da al semiólogo italiano la posibilidad de afirmar que los textos tienen algo que 'decir', o sea, que pueden y son percibidos y recibidos (interpretados) como contenedores y/o portadores de sentido justamente porque la apuesta inicial del receptor respecto del proceso de interpretación otorga -aunque hipotéticamente- una intención de sentido al autor, que al margen de su verificación, afirma que el texto quiere decirnos algo, o sea, pretende comunicar.

Ello resulta muy valioso para los fines de este trabajo, toda vez que encontramos en Eco la explicación de una relación convergente entre el arte y el lenguaje, y el arte y la comunicación, misma que se sostiene en la pertinencia semiótica del proceso interpretativo que imbrica al lenguaje como un modo de hacer que "dice", "expresa" y comunica, y no como mera estructura sin sentido. ${ }^{13}$ Para Eco resulta evidente que la interpretación es la clave de todo, pues la interpretación la hace el sujeto y en consecuencia pertenece y se inserta en el campo de sus competencias.

\footnotetext{
${ }^{13}$ En una posición contraria al enfoque sincrético de Eco, se hallan los estudios sobre el signo visual del Grupo $\mathrm{Mu}$, para quien el sistema sintáctico de un texto constituye, estructuralmente hablando, el punto de partida y de llegada de lo semiótico, por lo que la distinción entre lenguaje (entendido como retórica, código, sintaxis) y comunicación (vinculado con los significados y la transmisión de esos significados) se hace mucho más enfática y desmembrada.
}

La dimensión comunicativa del arte. $\bullet_{\mathrm{I}} 33$ Apuntes para un estado de la cuestión 
Desde la semiótica de la cultura, Iuri Lotman, entiende al arte como un lenguaje en tanto posee contenido, es decir, información. Para el autor, dicho contenido se manifiesta tanto en su posibilidad de ser transmitido (comunicado) como en su capacidad para ser interpretado. Pero advierte que para poder comprender una obra de arte es preciso entender su lenguaje, que no es más que un sistema modelizador que al tiempo que comunica, ordena y jerarquiza la información transmitida. ${ }^{14}$ Para sostenerlo, Lotman parte de que el arte es un sistema de modelización secundario que se sirve de la lengua natural como material, cuyo contenido conceptual está expresado en su estructura, proponiendo sustituir con ello la diferencia entre forma y contenido por la idea única de estructura artística, a cuyo cobijo se gesta. Para Lotman el texto artístico posee una alta densidad semántica y por ello produce pluralidad de lecturas, de ahí que conciba al arte como el procedimiento más económico y más compacto de transmitir información, pero al mismo tiempo como la puesta en escena de un lenguaje propio que se codifica solamente de una manera específica en el texto artístico y no en otro (Lotman, 1988, p. 17).

\section{LA DIMENSIÓN COMUNICATIVA DEL ARTE:} APROXIMACIONES TEÓRICO-METODOLÓGICAS

En este apartado describiremos tres enfoques teóricos y metodológicos que abordan en la actualidad las relaciones entre arte y comunicación, a partir tanto de la reflexión teórica como de la investigación empírica. El primer enfoque parte de una postura básicamente estructural que concibe a la comunicación artística como un proceso regido por las reglas de ciframiento/desciframiento codicial. Los otros dos se agrupan bajo el manto conceptual de la Escuela de Constanza o enfoques teóricos sobre Estética de la Recepción.

\section{2.o. I. La comunicación artística, un modelo cerrado}

La comunicación artística es un ámbito de la comunicación poco estudiado. La semióloga belga Nicole Everaert, a través de su Teoría de la Comunicación

14 "Todo lenguaje del texto artístico es en esencia un determinado modelo artístico del mundo, y en ese sentido, pertenece, por toda su estructura, al "contenido" que es portador de información" (...)"( Lotman, 1988, p. 11); "La complicada estructura artística, creada con los materiales de la lengua, permite transmitir un volumen de información completamente inaccesible para su transmisión mediante una estructura elemental propiamente lingüistico" (Lotman, 1988, p. 4).

I 34 - Vivian Romeu Aldaya 
Artística, parte de la diferencia kantiana entre la percepción de lo real y la percepción de lo posible para argumentar que el ser humano posee una facultad intermedia entre los ámbitos del razonamiento y la imaginación fantasiosa que le permite estar en contacto con "lo posible" y plasmarlo. Por lo posible, entiende, a partir de la noción de primeridad propuesta por Peirce (1987), lo que está sólo en la Idea, es decir, lo que es susceptible sólo de "ser dicho", pero no es "dicible" en absoluto. Según Everaert (2005), el artista, en el proceso de creación entra en contacto con lo posible, y mediante la producción de la obra -que es un existente singular ${ }^{15}$ - "infiltra" lo posible en lo simbólico.

Este proceso de infiltración, al decir de la autora, es lo que permite la construcción de una "puesta en común" de los mapas de la obra, pero dichos mapas no se despliegan a partir de una red simbólica conocida del todo, sino que en la medida en que la Idea se traduce a lenguaje mediante el proceso de creación, "lo posible" adquiere estatus simbólico o significante, operación que posibilita la potencial aprehensión de dicho simbolismo por parte del receptor a través del proceso de lectura.

El papel del artista en este proceso de infiltración es dejar plasmadas las "pistas" que deberá descubrir el receptor para llevar a cabo su proceso de descodificación. Pero para Everaert (2005), resulta determinante el hecho de que la comunicación artística tiene lugar siempre y cuando el receptor descodifique los mapas simbólicos cifrados por el autor en la obra, restituyendo así el sentido de la misma. Por ello la autora entiende al proceso de recepción de una obra como proceso de descodificación que completa el de la comunicación artística, hurgando en su estructura, en su código para hallar, más allá del estilo o el género, la red simbólica que la articula, o sea, los sentidos que la obra posee per se, y que han sido puestos ahí gracias a su autor, sea éste consciente o no de ello.

\subsubsection{La estética de la recepción, enfoques diversos}

Al decir de Mercedes Ortega (2004) la validez de la diversidad de lecturas, la caída del sentido único y universal de la obra y la plurisignificación generada a partir de sus potencialidades de sentido son las conciliaciones más generales a las que llegan los diferentes enfoques teóricos en los estudios sobre la Estética de la Recepción ${ }^{16}$, mismos que pueden ser agrupados bajo dos tendencias principales:

\footnotetext{
${ }^{15}$ Esto sería segundidad para Peirce.

${ }^{16}$ Las diferencias a veces irreconciliables entre los diversos enfoques teóricos y metodológicos de la Estética de la Recepción plantean un serio problema para erigir a estos estudios en teoría.
}

La dimensión comunicativa del arte. $\bullet_{135}$ Apuntes para un estado de la cuestión 
la de Hans Robert Jauss y la de Wolfgang Iser. A pesar sus diferencias, ambos parten de la lógica hermenéutica de Gadamer ${ }^{17}$ para quien de un texto sólo puede ser percibido aquello que tiene alguna relación con el sujeto que interpreta.

En su revisión de la obra de Gadamer, Jauss sustituye el término de fusión de horizontes ${ }^{18}$, por el de "horizonte de expectativas", en tanto este ultimo constituye la suma de comportamientos e ideas preconcebidas que hay en una obra, tanto al ser realizada por su autor como al ser valorada por los receptores. Dicha valoración tiene lugar por medio de lo que Jauss (2002) denomina proceso de identificación, donde ocurre tanto el reconocimiento del sujeto en la obra como el reconocimiento del conjunto de ideas preconcebidas de antemano por el receptor respecto a lo que la obra le muestra. De esa manera en la identificación el receptor 'acorta' su distancia respecto de la obra en tanto la reconoce, la juzga y la interpreta de acuerdo con su propio horizonte de expectativas. ${ }^{19}$

El segundo enfoque es el que propone Wolfgang Iser, a partir de las concepciones de Ingarden (citado en Iser, 1997), quien concibe a la obra como esqueleto o esquema que debe ser completado por la interpretación del destinatario. Iser parte de una distinción entre los conceptos de texto y de obra, entendiendo al texto como pura potencialidad, y a la obra como lo que el lector reconstruye a partir de la configuración concreta de dicha potencialidad. Sin embargo, al igual que Ingarden, Iser afirma que las reglas del juego interpretativo las pone el texto. Sin embargo, para el autor, la verdadera manifestación del texto es la concretización, es decir, la lectura o recepción del texto en un sentido estético que para él se traduce en la confluencia dialógica entre los elementos pertinentes del texto ${ }^{20}$ y la interpretación de dichos elementos por parte del lector. Como

\footnotetext{
${ }^{17}$ Gadamer afirmaba que la respuesta que ofrece un texto al indagar sobre él nunca es suficiente, es decir, no lo agota, pues el propio texto plantea preguntas al receptor que éste tendría que responder, con lo que en esta dialéctica obviamente se gestaba un texto nuevo que era el resultante de las preguntas y las respuestas contenidas en ella. Sin embargo, a la interrogante sobre el tipo de preguntas que el receptor podía construir para intervenir el texto, Gadamer respondía que éstas sólo podían provenir del horizonte de preguntas históricas que el sujeto era capaz de hacerse. Y a esto le llamó fusión de horizontes, de manera que dicha fusión "objetivaba" tanto a la obra como al proceso interpretativo que realizaba el receptor.

${ }^{18}$ Ver nota anterior.

${ }^{19}$ En ese sentido, parece evidente que el vínculo de Jauss con las tesis hermenéuticas de Gadamer lo llevan a privilegiar una postura sobre la recepción estética que da crédito solamente a la interpretación del receptor mediante la identificación como único camino posible hacia ella.

${ }^{20}$ Para el autor, los elementos pertinentes son los elementos significantes de la obra. Es decir, se trata de elementos significativos en su potencialidad.
}

I36 Vivian Romeu Aldaya 
puede notarse el texto así entendido, puede revelar una multiplicidad de conexiones potenciales que derivarían teóricamente al menos, en una infinidad de interpretaciones y en una concepción ilimitada de la interpretación. Quizá no sobra acotar que para el autor esta tarea es posible en tanto depende más del texto que del receptor en el sentido de que las conexiones varían de un individuo a otro, pero sólo pueden realizarse dentro de los límites impuestos por lo que está fijo y dicho en el texto en oposición a lo que no está dicho. Para Iser (1987) el proceso de configuración de los significados constituye una instancia de libertad que le permite al lector configurarlo de algún y cualquier modo, por lo que cualquier configuración resulta válida a sus ojos.

\section{A manera de resumen, El Cierre}

Como hemos visto, la definición del arte como lenguaje, y las consecuencias que esto implica para el entendimiento y la caracterización del panorama conceptual de las relaciones entre arte y comunicación, hunde sus raíces en el seno de la filosofía, la estética, la sociología y la semiótica fundamentalmente. Pensadores de diferentes campos han abonado el terreno en ese sentido, y el mapeo inicial de estas reflexiones, han sido separadas en este trabajo en dos áreas diferenciadas: la primera que trata la diversidad de reflexiones que abordan el eje temático que nos ocupa y que hemos construido a manera de antecedentes a través de lo que denominamos 'nodos conceptuales'; y la segunda, que se enfoca a la descripción crítica de los principales enfoques teórico-metodológicos que desde la comunicación intentan teórica y empíricamente sostener y consolidar la idea de que el campo del arte y el campo de la comunicación se hallan estrechamente vinculados. En ese sentido, y a manera de cierre, nos interesa resumir aquí lo que consideramos resulta más significativo de la revisión que hemos realizado.

Tomamos de Aristóteles la idea de que la mimesis como proceso genera verosimilitud, en la medida en que ésta se establece como reconocimiento en función de la creación de un efecto en el receptor, que entendemos como efecto de comunicabilidad. Este postulado que Aristóteles concibió como Verdad está presente también en Kant, Hegel Adorno, Gadamer, Heidegger y Pareyson, aunque de diferentes maneras; sin embargo, ello no impide que de una forma u otra estos pensadores conciban al objeto estético como objeto que enuncia autosuficientemente la Verdad, lo que en términos comunicativos no busca asociarse con las verdades universales ni las esencias de las cosas, sino

La dimensión comunicativa del arte. $\bullet_{137}$ Apuntes para un estado de la cuestión 
como verdades textuales y contextuales configuradas en la obra y por ella, y en consecuencia merecedoras de respeto en tanto constitutivas de otredad. Así, el artista en tanto hombre de su tiempo, a través de los procesos de creación en los que está inmerso, interpreta su realidad y la plasma.

Pero el acto interpretativo, de acuerdo al postulado hermenéutico de Gadamer resulta del recorrido que hace el sujeto para reconocer y reconocerse en la obra, reconociendo con ello el entramado de la Historia y sobre todo de su historia individual, de la dialéctica entre lo uno y lo múltiple, lo mismo y lo diferente, lo que conduce a entender la interpretación como instancia de búsqueda, de diálogo, de interacción. Ello presupondría una arquitectura comunicológica que al mismo tiempo fuera constitutiva y constituyente de los procesos comunicativos en tanto interpretación. En consecuencia, la interpretación, ya sea vista en forma de conocimiento (Aristóteles, Adorno, Hegel) o autoconocimiento (Adorno, Gadamer, Heidegger), resulta una actividad creativa que puede ser entendida también como lenguaje; lo que indica que el arte en tanto forma y contenido es interpretado tanto por quien lo produce durante el proceso de creación, como por quien lo recibe durante el proceso de recepción. Por ello, es justamente en la interpretación donde la concreción semiótica entre texto y receptor afirma las relaciones entre arte y lenguaje, y entre arte y comunicación. Mientras en el proceso creativo (que no olvidemos que se trata de interpretación también) el autor convoca necesariamente al lenguaje ${ }^{21}$ para "formar" a la obra, esa misma obra adquiere dimensiones de realidad cuando el receptor la aborda interpretativamente, y precisamente ahí cobra estatuto comunicativo.

Justamente de esas conclusiones se nutren la teoría de la comunicación artística y los enfoques teóricos de la Estética de la Recepción para desarrollar sus propuestas sobre la comunicabilidad del arte, o sobre las formas en las que interviene la comunicación en los procesos de recepción del arte. De ahí que sean fácilmente identificables las tres corrientes principales alrededor de las cuales se construye el panorama de las relaciones entre arte y comunicación, ella son: la que plantea que el arte comunica porque posee comunicabilidad intrínseca al interior del objeto estético; la que señala que no es relevante plantear si el arte posee comunicabilidad o no, sino que cifra las relaciones entre arte y comunicación en la dimensión de la recepción y los procesos de lectura: y aquella que

\footnotetext{
${ }^{21}$ Por lenguaje estamos entendiendo todo sistema que ponga en relación a unos elementos con otros.
}

I38 Vivian Romeu Aldaya 
enfatiza la comunicabilidad estética a partir de la relación entre objeto estético y sujeto receptor, a partir de la interpretación respetuosa y mutua.

Como se puede observar, el panorama anterior muestra al menos tres posturas que teórica, conceptual y metodológicamente plantean serias diferencias entre sí. El desarrollo paralelo de cada una de estas líneas contribuiría sin dudas a complejizar la mirada en torno los vínculos entre arte y comunicación, pero al mismo tiempo posibilitaría el enriquecimiento de las reflexiones sobre cada uno de los campos como tal. Como abordamos al inicio de este trabajo, nuestra revisión tomó como premisa de partida al concepto de diálogo en tanto propiedad de la interlocución, y a la interlocución como dimensión de lo comunicativo. En ese sentido, la breve y apurada revisión que aquí se ha presentado constituye si bien una exploración necesaria, sin duda también un acercamiento incompleto.

\section{ReFERENCIAS}

Adorno, T. (1983). Teoría Estética. Buenos Aires: Orbis Hypamerica Ediciones Argentinas.

Aristóteles. (1985). La poética. Versión de Juan David García Bacca. México: Editores Mexicanos Unidos.

Bourdieu, P. (1990). Sociología y cultura. México: FCE.

Bourdieu, P. (1995). Las reglas del arte: génesis y estructura del campo literario. Barcelona: Anagrama.

Calabrese, O. (1997). El lenguaje del arte. Barcelona: Paidós.

Collingwood, R.G. (1960). Los principios del Arte. México: FCE.

Danto, A. (2002). La transfiguración del lugar común. Barcelona: Paidós.

Della Volpe, G. (1987). Historia del gusto. Madrid: Visor, Madrid.

Eco, U. (1990). La definición del arte. México: Martínez y Roca.

Eco, U. (1992). Los limites de la interpretación. Barcelona: Lumen.

Everaert-desmendt, N. (2005). "La comunicación artística: una interpretación peirciana". Signos en rotación Año III No. 18, 2005. Recuperado en diciembre de $2007 \mathrm{de} \mathrm{http://www.unav.es/gep/Articulos/SRotacion2.html}$

Gadamer, H. G. (1991). "La transformación del juego en construcción y la mediación total", en Verdad y Método I. Salamanca: Editorial Sígueme.

Goodman, N. (1976). Los lenguajes del arte. Barcelona: Seix Barral.

Goodman, N. (1990). Maneras de hacer mundos. Madrid: Visor.

Hauser, A. (1994) Historia social de la literatura y el arte I, II y III. Colombia: Editorial Labor.

Heidegger, M. (1983). Interpretaciones a la poesia de Holderlin. Barcelona: Ariel. Iser, W. (1987). El acto de leer. Madrid: Taurus.

La dimensión comunicativa del arte. $\bullet_{\mathrm{I}} 39$ Apuntes para un estado de la cuestión 
Iser, W. (1997). "El proceso de lectura: enfoque fenomenológico”, en Mayoral, José Antonio, Estética de la Recepción. Madrid: Arco.

Jauss, H.R. (2002). Pequeña apología de la experiencia estética. Barcelona: Paidós.

Kant, I. (1984). Crítica del juicio. Madrid: Espasa.

Lotman, I. (1994, julio-diciembre). "Para la construcción de una teoría de la interacción de las culturas (el aspecto semiótico)", en Revista Criterios No. 32, Cuarta Época, pp. 117-130.

Lotman. I. (1988). "El arte como lenguaje", en Estructura del texto artístico. Madrid: Istmo.

Lotman, I. (1999). Cultura y explosión. Lo previsible e imprevisible en los procesos de cambio social. Barcelona: Gedisa.

Mayoral, J.A. (1997). Estética de la Recepción. Madrid: Arcos.

Ortega, M. (2004). "Fundamentos de la Estética de la Recepción", en Revista La Casa de Asterion. Revista Trimestral de Estudios Literarios, Vol. V, número 17, abril-junio, 2004. Recuperado en marzo de 2008 de http://casadeasterion. homestead.com/v5n17estet.html

Peirce, C. (1987). Obra Lógico-semiótica. Sellected Writtings. Madrid: Taurus.

Ruspoli, E. (2000). "La filosofía del espíritu de Benedetto Croce: arte, filosofía e historia”, en Cuadernos de Filología italiana, 2000, número extraordinario, pp. 609-627. Artículo disponible en línea en: www.ucm.es/Bucm/revistas/ fll/11339527/articulos/CFIT0000330609A.pdf

Sánchez, A. (1982). Textos de Estética y Teoría del Arte. México: Ediciones unam.

Vilar, G. (2005). Las razones del arte. Barcelona: La Balsa de la Medusa, Colección Filosofía.

I $40 \cdot$ Vivian Romeu Aldaya 